\title{
Why we need to talk about learning spaces
}

\author{
Dr Brett Bligh, Lancaster University
}

\section{Introduction}

The 2017 instalment of the US New Media Consortium's annual Horizon Report: Higher Education edition foregrounded the importance of a pivotal trend for technology adoption in the higher education sector:

Redesigning Learning Spaces (Adams Becker et al, 2017, p3). It is a novel focal point: it runs against the grain of much everyday discussion about how technology influences human learning (and, indeed, broader repercussions for living and working). Technology in higher education has often been posed in opposition to space - seen as further undermining the importance of place with each passing year. The centrality of placebound lectures and seminars to the learner experience is, the story goes, being rapidly supplanted by the "anytime, anywhere" provision of digitalised forms of higher education (cf Crook and Bligh, 2017). Even for higher education institutions themselves, digital networks, it is suggested, underpin strategies for escaping established place-bound identities, as universities seek to become global prestige brands - 'located' in international flows of information and recruitment rather than in some physical territory (cf Tierney and Lanford, 2015).

Yet the Horizon report argues that Redesigning Learning Spaces is one of the six "key trends accelerating higher education technology adoption" (Adams Becker et al, 2017, p3). If the report's contributing panel of 78 education and technology experts in 22 countries is not badly mistaken, then a large sectoral trend with considerable impact is being profoundly under-recognised and misunderstood. That misrecognition is the starting point for the present piece of writing, whose topic concerns how researchers and other stakeholders are currently talking about physical learning spaces - and how we might talk about them differently in future.

The present piece starts from two core convictions: about higher education space itself, and about knowledge of that space. Those issues are closely linked, of course - and, to many, what is said will appear uncontroversial. But each, in turn, has consequences for how we can, and should, talk about learning spaces consequences that are often overlooked.

My basic convictions about space itself are twofold: that it remains a fundamentally important mediator of human learning, and that it is produced socially within institutions in contingent, contextualised ways.

Where institutions, educators and students take advantage of new technological developments, I suggest, their doing so does not render physical space less important. Instead, certain varieties of longstanding space, including some of the most taken-for-granted workhorses of higher education, are socially destabilised confidence in their continuing usefulness gets shaken to some extent. Meanwhile, proposals for new forms of space emerge, with varying physical forms and representing varying stakeholder interests. Advocates of these proposals seek to ensure they supplant more established designs by making claims about suitability for desired practices and technological realities - and sometimes by wielding a discourse of 'newness' ("a $21^{\text {st }}$ century learning space!"). Some new forms of space are actually taken up within institutions, and/or by some given teaching staff and students: those where key stakeholders have been adequately convinced by advocates' claims and not sufficiently discouraged by the required outlay. Conversely, other space designs are explored in sandpit settings, but for various reasons - justified or not - they do not get adopted more widely. In parallel, there is increased recognition of the centrality of various forms of off-campus or non-institutional space including domestic and external workplace settings, cafés and moving vehicles. Those spaces also come to be seen as 'new' learning spaces, notwithstanding that they may have had longstanding utility for particular 
segments of the student population, such as distance students, part-time students, commuters and those on professional placement.

One consequence is a heightened sense of contestation between myriad spatial forms, 'old' and 'new'. Whether closer examination of some 'new' space reveals it to be advantageous is, of course, uncertain. Some are eventually evaluated as less successful than the spaces they supplanted - though such evaluation is itself a contested institutional practice (Pearshouse et al, 2009). Nonetheless, changes in higher education space continue, in an ongoing way, within institutions. Spaces have varying degrees of influence on practices and experiences within institutions, and concurrently those practices and experiences have varying degrees of influence on the development of the learning spaces there.

My convictions about knowledge and discussion of higher education space build on this recognition that space production is, fundamentally, a human process. Space is institutional, social, contextual and historically developing as well as physical and technological; and the people involved have different interests, expertise, and authority. Such a complex reality provokes understandable uncertainty, frustration and anxiety, and key stakeholders are constantly vigilant for knowledge that appears to transcend that social messiness. If some researcher 'proved' that painting classroom walls in some shade of blue led to " $15 \%$ better learning", then such knowledge would be attractive to many stakeholders - in part, because what to do with this hypothetical knowledge would be very obvious (get painting!). Yet the search for absolute or universal knowledge about learning spaces in higher education is likely to lead to, at best, partial and one-sided understanding. Furthermore, in common with many other social domains of investigation, I suspect that much insightful knowledge about learning spaces in higher education will not arrive packaged in that way. Instead, I suspect that our understanding of learning spaces will necessarily be uncertain, relative, deeply contextualised and represent different interests; and that it will need to account for persistent problems of a sociocultural nature. For instance, where:

+ Stakeholders have different ideas about what some given space should do - about what is valued as successful (cf Bligh and Pearshouse, 2011);

+ Accounts of the effectiveness of a particular space in practice are contested;

+ Attempts to transplant the design of a space, which has been judged to be effective in one place, to another location fails to reap similar benefits; or

+ The knowledge and conviction of some stakeholders (including researchers!) is judged to be incomprehensible by some other stakeholders - who therefore cannot make use of it.

In the remainder of this piece, I build on the notion that knowledge about learning spaces should be viewed as valuable to the extent that it guides stakeholders' thinking about the goals of particular spaces, leads to better comprehension by stakeholders of the different interests and positions of others (acknowledging, though, that comprehension is often rather different to consensus) and highlights the contextualised nature of how spaces work. Most of all, it is valuable if it provides a common vocabulary for reflection, exploration, discussion and debate. Those value judgements, of course, are closely linked - they are all fundamentally concerned with how we talk about learning spaces.

Below, I suggest my own research-derived vocabulary - one that can, I suggest, help stakeholders to conduct discussions and produce their own knowledge about learning spaces. Firstly, however, I set out a brief overview of the current state of scholarly knowledge and discussion about learning spaces in higher education.

\section{The research discussion about learning spaces}

Let us commence the discussion of academic research about learning spaces by returning to the Horizon report. Its advocacy of the Redesigning Learning Spaces theme is set out as follows: 


\begin{abstract}
"As universities engage with strategies that incorporate digital elements and accommodate more active learning in the physical classroom, they are rearranging physical environments to promote these pedagogical shifts. Educational settings are increasingly designed to support project-based interactions with attention to greater mobility, flexibility, and multiple device usage. To improve remote communication, institutions are upgrading wireless bandwidth and installing large displays that allow for more natural collaboration on digital projects. Further, universities are exploring how mixed reality technologies can blend 3D holographic content into physical spaces for simulations like experiencing Mars by controlling rover vehicles, or to enable multifaceted interaction with objects, such as the human body in anatomy labs, with detailed visuals. As higher education continues to move away from traditional, lecture-based lessons toward more hands-on activities, classrooms are starting to resemble real-world work and social environments that foster organic interactions and cross-disciplinary problem-solving." (Adams Becker et al, 2017, p9)
\end{abstract}

It is worth noticing that much of what is described - a lecturing-is-dead agenda and the accompanying advocacy of project-based working, an emphasis on the mobility of learners and their use of multiple personal devices, excitement about the possibilities for remote communication and educational simulations - is not, in itself, so extraordinary. Such tropes have been a stock-in-trade of institutional educational technology communities and staff development courses for a good while. In some ways the only thing that is new here is the recognition of the spatial consequences. Yet the relations between technology and space in Horizon narrative are quite unidirectional: changes in technology are seen as both preceding and driving changes in space. Furthermore, in some instances, space seems described mainly as a container for technology, rather than as mediating practice itself. Clearly, the intended audience for the Horizon reports (policymakers interested in technology trends) will influence the narratives adopted. Yet the narrative here is hardly atypical: reflecting, in my view, lack of confidence and conceptual maturity in discussing space. The consequence is that prominent narratives seek legitimacy for learning spaces by invoking association with other, more prominently recognised phenomena. In this case, developments in technology sectors are invoked, but other discourses might equally draw on narratives about the popularity of part-time and distance education, the funding of higher education systems and changes in recruitment and student aspirations within a globalising economy.

What we can detect, then, is that learning spaces is an underdeveloped research field by contrast with those focusing on many of the other issues with which it necessarily interacts. Although there are sharp disagreements about how the effects of technology on educational practice should be conceptualised - see the report by Luckin et al (2012) for an extended discussion - there exists a substantial international and interdisciplinary evidence base, and a wide range of journals and conferences, on the topic. The same cannot be said for research on learning spaces.

A sense of being a poor relation has long permeated the small literature on the topic. An influential review article by Paul Temple (2008), for example, conveys the message even in its title - Learning spaces in higher education: an under-researched topic. "The study of learning spaces in higher education," says Temple in the introduction to the piece, "has not historically attracted a great deal of attention from scholars or researchers; the work of higher education has, implicitly, generally been considered as taking place independently of the spaces in which it was located" (p229). Temple's statement correctly implies that the paucity of research into learning spaces is especially disappointing because research into higher education more generally is burgeoning. Tight (2012), for example, reviews the wealth of higher education books and journals being published: his conspectus reveals that the issues receiving most attention are teaching-learning, the student experience, institutional management, academic work, system policy, quality and course design. Many of those categories actually look like fairly promising sanctuaries for some discussion of higher education learning spaces. Yet, alas, the issue is mentioned in passing on a single page across the 230 pages of text - something of an indictment of the underlying material that Tight is summarising.

Such widespread scholarly indifference has not, of course, prevented estates managers from investing, or students from changing preferences. As a consequence, there has been a pervading sense of double 
inadequacy - that research on learning spaces receives scant attention by comparison to the enormous institutional investment in the spaces themselves, as well as in relation to research on proximate topics.

The obvious objection here is that, in the decade since Temple published his article, there has been an upwards trend in the scholarly investigation of learning spaces. However, I contend that the progress made has been incremental rather than radical in nature. Let us consider three more recent review articles to illustrate that point:

+ A report by Painter et al (2013), which examines evidence about space design;

+ A scoping study by Nordquist (2016), which focuses on relations between space and curriculum as they play out specifically within the disciplinary education of the health professions; and

+ A conceptual review by Ellis and Goodyear (2016), which aims to unpick the myriad influences of learning spaces on student learning activities.

Each of those review pieces highlights, in different ways, that research over the last decade has focused extensively on unpicking whether learning space design makes any discernible difference to a variety of stakeholder experiences and learning outcomes and reaching conclusions to the affirmative. A core point of emphasis, then, is on legitimising learning spaces as a research topic - understandable, of course, given widespread distrust about whether space is important at all.

For example, Painter et al (2013) highlight how their findings support notions that formal space redesign can indeed influence the classroom practices of both teachers and students, and that the broader campus-level experience does indeed influence student satisfaction and retention. Nordquist (2016) highlights accumulating evidence from a range of studies that compare particular classroom designs on a bilateral, quasi-experimental basis: among other things, Nordquist concludes that there are credible and positive results showing that new classrooms designs can indeed promote various aspects of learning (such as dialogue). On the other hand, there is certainly some hedging going on in these reports. For example, Nordquist counterpoints his positivity about space influencing learner practices by suggesting that, if teachers' behaviours are also to change, then the evidence is that space redesign alone will not be sufficient: active institutional faculty development strategies will also be required. What we have, therefore, is a narrative of legitimation that uses a sense of "positivity with conditions attached" as its ground. In my view, however, it is precisely questions relating to how learning spaces are effective under particular conditions that we need to explore.

Alongside those attempts at legitimation within the reports sit a range of particular gap spotting narratives. While such narratives are, of course, commonplace in scholarly review articles, what is noteworthy here is that many of the actual gaps being identified are framed as concerning research into particular space types. We have more research into room types $x, y$, and $z$ than into room types $a, b$, and $c$ ! One particularly systematic variant of that narrative is offered by Ellis and Goodyear (2016), who position the studies they find along three axes: based on distinctions between teacher-managed and more informal spaces; between spaces provided by universities, by third parties and by students themselves; and between physical, virtual and hybrid spaces. Ellis and Goodyear's analysis highlights - among other things - that the literature focuses a heavy proportion of its attention towards research on the configuration of formal learning spaces and, in a somewhat separate strand of inquiry, towards student experiences in informal learning spaces (such as university libraries).

I do not wish to suggest, I should emphasise, that those full ranges - or the different kinds of spaces within them - are not worthy of investigation. There are, in point of fact, some interesting observations to be made even by interrogating the points of dissonance between the reviews. For example, Painter et al (2013) and Ellis and Goodyear (2016) each highlight a considerable interest in student experiences in informal learning spaces, whereas Nordquist (2016), with his more particular focus on education of health professionals, bemoans a dearth of research on the same issue. My reading is that the discrepancy is itself interesting: it highlights how perhaps too much of the research on student experiences in 'informal' spaces assumes that both the spaces and the experiences therein are not disciplinary. In turn, that implies a discomforting critique of how learning 
spaces scholarship routinely compartmentalises the issue of academic discipline when investigating learning in higher education.

Yet, in light of my previously stated convictions about knowledge about learning spaces, my overarching reaction to those gap spotting narratives should be obvious: even where individual space types seem well covered by empirical investigation, that knowledge will only be useful if it takes into account the context of sociocultural practice rather than being viewed as applicable to all instantiations of those space types in universal terms. Indeed, from my perspective it would be more directly useful to map the research according to the sociocultural practices and experiences that are being described - and to highlight the gaps in the literature on that basis.

It should be noted that the three reviews do differ somewhat in the kind of knowledge about learning spaces that they suggest are valuable. The narrative arc in the review by Painter et al (2013) is particularly interesting in this regard. Early on in their report, the authors draw attention to how previous generations of learning spaces researchers - they refer to efforts in 1950s-70s US - foundered on precisely this issue:

\begin{abstract}
"Over the next 10 years, however, it became clear that psychology research paradigms were not set up to respond to the specific questions posed by the architecture, design, and planning professions and the kind of immediately applicable information these disciplines were seeking was not forthcoming. Aside from standards generated in the field of ergonomics for sizing spaces and furnishings to fit the human body, architects and designers did not receive the fact-based data trove they had hoped for. As a result, the potential connections between these two realms of knowledge were never solidified, and by the 1980s architects and designers had gone down their own pathways." (pp4-5)
\end{abstract}

It is interesting, however, to contrast those initial observations against Painter et al's own recommendations for the field, as presented at the end of their report. Those recommendations include creating "an agreed upon taxonomy of learning space" ( $p 29$ ), producing "measures of behavior" that meet "the benchmark of reproducibility" (p29), and focusing more on "learning outcomes" (p30). Ultimately, it is difficult to escape the conclusion that Painter et al's suggestion for a future learning spaces research agenda - "rigorous, systematic, reproducible, and longitudinal inquiries that will yield insight into what works and what does not" - largely fails to escape universality of the "psychology research paradigms" of which they were earlier so disparaging.

To different extents, the reviews by Nordquist and by Ellis and Goodyear track a different path, with the latter authors in particular drawing attention to a range of emerging "representations and models" of learning spaces. "The purpose of doing this", Ellis and Goodyear state, "is to help people working in the emerging field of learning space research recognise commonalities and differences in what are sometimes quite implicit conceptualisations of relations between space and learning" (p173). I, of course, concur with that position, but it seems clear that many of the models that their review actually uncovers within the literature are ill-suited to addressing those aspirations. Ellis and Goodyear themselves acknowledge the attendant problems:

"In addition to the dangers of relying on 'everyday' or unexamined concepts, fragmented conceptual frameworks impede collective advances in this field - it is unnecessarily hard for researchers and practitioners to see how new findings and insights build on what is already known if there is not some framework on which to build commonality of understanding." (p173).

At present, as Ellis and Goodyear highlight, the literature seems dominated by generalised representations (with the words 'space' and 'learning' placed within concentric circles, or connected by arrows); by typologies of learning spaces; and by process models that abstract away from the actual practices of teachers and students (pp175-179). Ellis and Goodyear do present their own "activity-centred" models of how we might see space as integral to human practice: sketching two models focused, respectively, on relations between activity, tasks, tools, people and outcomes ( 179 ), and between social situation, physical situation, goal-directed action, embodied cognition, tasks and outcomes (p180). Yet Ellis and Goodyear go on to conclude their review by arguing the following: 
"The review presented in this paper has a number of implications for future research involving university learning spaces. It suggests that studies of the connections between attributes of physical and/or virtual space, on the one hand, and student learning outcomes, on the other, need to pay attention to mediating factors - with close attention to what students actually do and the sense they make of what they do." (p181)

It is here that I concur most strongly with Ellis and Goodyear. It is my position that conceptualising how space is a "mediating factor" within the actual practices of higher education is a core aspiration, to which the scholarship on learning spaces has yet to provide any kind of satisfactory answer. The vocabulary I outline in a subsequent section of this piece is oriented towards precisely that issue of how space mediates practice.

\section{A new vocabulary for discussion}

In what follows, I have specifically attempted to create a vocabulary that is underpinned by research into learning spaces. ${ }^{1}$ The reason for doing so is to support the possibility of boundary crossing between the conversations about learning spaces going on institutions, and debates occurring in the scholarly literature.

The specific piece of research that I am building on is an earlier piece co-authored by myself (Bligh and Crook, 2017). In that piece, Charles Crook and I attempted to categorise and conceptualise the various ways in which research papers published in educational research, technology enhanced learning and human-computer interaction venues discussed space as a mediator of educational practice. It should be emphasised that the vocabulary proposed here varies to a considerable degree from that earlier academic framework: it is inspired by that previous work rather than identical to it. Whereas the earlier piece categorises research stances, some of which carry distinctly normative views, the present piece is oriented towards encouraging stakeholders to reflect on their experiences and explore future possibilities within their particular institutions. It should also be emphasised that the proposed vocabulary deliberately bears very little relation to those specialised terms that are used by estates, engineering or architectural professionals; or within institutions to produce legalistic specifications for external tender documents or post-occupancy evaluation specifications.

Finally, it should be emphasised that the vocabulary presented below is not intended to be immediately intuitive or obvious. Instead, the vocabulary is intended to support reflection, re-thinking and re-conceptualisation - as stakeholders use it to explore their experiences and aspirations together.

The vocabulary I shall propose is based around six core concepts, wherein space is understood to be transparent, enabling, stimulating, associative, cognitively integrated and socially integrated. Those concepts are briefly represented on a poster, reproduced here, which I hope can be used to provide a friendly overview when stakeholders come together to discuss institutional space production (Figure 1). Each of those concepts opens up different possibilities for discussion and invites stakeholders to focus on a range of closely related issues, for which a range of supporting terms are also provided. Those concepts are outlined in sequence in the following six subsections, along with some reflection about the range of issues that stakeholders might wish to discuss in each case.

\footnotetext{
${ }^{1}$ Here, I shall not prescribe specific activities within which this vocabulary might be used, since the possibilities are legion, although I have written about that topic before elsewhere (Bligh, 2014).
} 


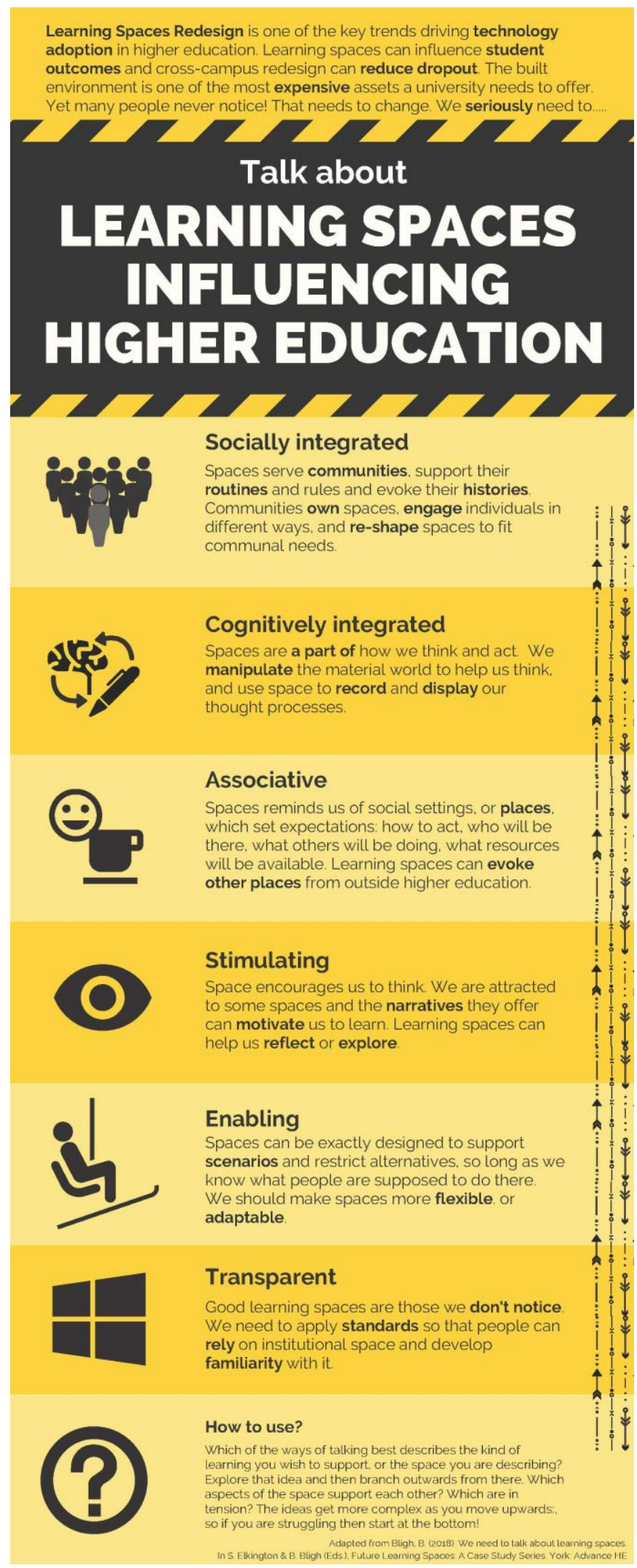

Figure 1: A poster overview of the vocabulary for talking about learning spaces. ${ }^{2}$ 


\section{The transparent learning space}

The transparent learning space goes unnoticed by those using it to undertake educational work; the needs of the people working there have been predicted in advance and provided for in such a way that the space recedes to the periphery of their attention. That mode of mediation is possible because the transparent learning space is built upon well-considered standards. Some of those standards are derived from legal and professional frameworks that stipulate minimum or ideal levels for room temperature, lighting (including natural light), working space per person, and so on. Yet other standards are more noticeably local - such as where all teaching rooms across an institution are provisioned with the same technological control system, to increase the likelihood that people entering a given room will already be familiar with how to switch on the required devices.

The transparent learning space invites several assumptions: that what people will want to do there is to some extent predictable; that the task is to provide space that is adequate for the predicted purposes; that familiarity with other spaces can be used to support a cumulative, disappearing effect of transparency; and that learning does not depend on conscious interaction with aspects of the space. Any and all of these assumptions might be debated by stakeholders with reference to particular spaces. Of course, the transparent learning space might be a fragile construction. Whenever users must modify their learning practices because of available resources or spatial configuration, feel uncomfortable or irritated by some aspect of their surrounding environment, or indeed need to direct their attention to the space for any reason whatsoever, then the transparency of the learning space has been compromised. The extent to which that compromise is justified or even desirable - is an important topic for discussion, especially in contexts where stakeholders are pushing for innovation to occur. Historically, estates and IT personnel within the institution might have sought to produce and maintain the transparency of learning spaces with little input from denizens; indeed, while space users might be consulted at predetermined moments in estate lifecycles, the very notion of transparency might be seen as mitigating against continual input from space users. One issue for discussion might concern the desirability of ongoing feedback from denizens about particular spaces, and how those sources of feedback might be integrated - so acknowledging both the localised experiences of denizens and the legitimate desire of estates personnel to maintain standard specifications across some range of spaces. The inherent tension within the concept of the transparent learning space concerns the extent to which educational practice is supposed to be carried out without regard for space or in otherwise frictionless ways; that tension invites us to consider what is supposed to be transparent and what is not.

\section{The enabling learning space}

The enabling learning space is a deliberately configured container that supports and resources a range of desired educational practices. The physical layout of the space invites, or makes it easier, for people to operate in particular ways; and, conversely, it may also work to discourage other forms of practice. That mode of mediation is possible because the space has been conceived as supporting definite forms of practice and thereby configured in exact ways; its form may radically diverge from other enabling learning spaces that aim to support other practices. That sense of particularity, or exactness, pervades the design.

The enabling learning space works by allowing its denizens to move in particular ways, to comfortably inhabit particular locations and postures, to access the particular resources they need to perform particular tasks close-at-hand, and to see and hear particular elements across the room - including, perhaps, other people and the resources they are using. The enabling learning space often offers flexibility, providing wheeled tables and other movable resources that allow denizens to reconfigure the space upon entry and to shift between different modes of practice at different moments within the same overall session. Yet the enabling learning space remains deliberately configured - that flexibility is not usually understood as an unrestricted charter for denizens to do anything they like, but rather as providing for convenient movement between different scenarios that are themselves still particular. Indeed, the enabling learning space may often also be a constraining learning space, one deliberately designed to exclude certain forms of action and reconfiguration. Where a room 
has been configured to promote scenarios of small group working, for example, then practices of whole-class lecturing might be deliberately constrained by the provision of restricted sight lines that encourage teachers to rove between groups. Quite how and what a particular space enables and constrains, and the range of scenarios anticipated by the flexibility of the design offered, are, therefore, issues that need to be considered as mutually related within stakeholder discussion. The role of estates and IT personnel in orchestrating the enabling learning space has generally been to anticipate the particular needs of denizens, while managing the extent of possible change within the room in line with the spirit of its design. At a micro-level, doing so may be achieved by enforcing room layout rules: such as insisting that rooms must be returned to their original layout by close of session. Estates personnel may also have a preference for vocabulary of adaptability, which implies a focus on the professional management of changes to room configuration over time, rather than flexibility, which might be perceived negatively as unstructured, chaotic and permissive - allowing denizens to engage in inappropriate behaviour. That distinction is certainly worthy of discussion, since it seems plausible for mutual enlightenment to occur - including where denizens may come to see the value in those rhythmic, seasonal changes implied by the concept of adaptability. The inherent tension within the enabling learning space, therefore, concerns the particularity of the enabled practices and the degree of constraint and control that is to be enforced upon denizens; a tension that is sometimes manifest through establishing definitions of adaptability and flexibility for particular rooms (or room types) within institutions.

\section{The stimulating learning space}

The stimulating learning space is designed to provoke thinking and action through sensory experience and, most typically, is permeated by a desire to prompt curiosity and reflection. The stimulating learning space works by providing experiences organised around artefacts that are of interest to its denizens; and by contextualising those artefacts in ways that emphasise their relevance to educational practices - and to the other artefacts in the space - within overarching narratives. Denizens are being invited to explore the space and so to traverse the narrative. That exploration might involve ambulatory movement, such as walking around a university exhibition space or campus garden; but equally it might involve remaining in one location, perhaps seated and enjoying a moment of quiet reflection while looking at an information display or piece of artwork. Moreover, the exploration might be undertaken in a variety of social configurations, encompassing experiences ranging from the relatively gregarious (exploring with others, discussing, arguing, laughing, shouting) to those that are apparently solitary (exploring on one's own, engrossed in quiet thoughts and dialogue with oneself). What remains central is the provoking of sensory experience, most usually in the form of visual experiences but very plausibly including experiences based around the other human senses as well. It might be possible, for example, to provoke curiosity based on sensory experiences of touch or manipulation, or smell, or even by depriving particular senses - as is achieved when rooms are darkened. The narrative of the space, the senses that are to be stimulated as denizens explore, and the character of the sociality that ought to permeate the experience - all of these should form interesting bases for stakeholder discussion.

Two points of tension for the stimulating learning space concern the extent to which the narrative organisation is, firstly, prescriptive and, secondly, directly related to formal learning outcomes. In some cases, what is provoked might be more 'open-ended' experiences in both senses; some versions of the stimulating learning space may even manifest concerns oriented more towards affect and wellbeing than to cognitive knowledge acquisition per se. The engineering space that ostentatiously 'displays' those aspects of its construction that are relevant to the course being studied, the quiet garden where natural light and plant life help students to relax in the quiet moments of a busy day - both are, equally, instantiations of the stimulating learning space. Another point of tension concerns the extent to which denizens are empowered to alter or co-design the stimulating learning space. The most obvious metaphor for the design and management of the stimulating learning space and its artefacts by professional staff is curation, and exploring the meaning of that metaphor for a particular space might serve to open up questions of who the curators are and what power is accorded them. 


\section{The associative learning space}

The associative learning space is designed to evoke feelings and expectations at an intuitive level. The associative learning space works by mimicking aspects of other spaces that its denizens will likely already be familiar with: cafés, domestic settings, corporate boardrooms, industrial plant and museum galleries are among the more prevalent choices. That mimicry may involve importing isolated elements of those other spaces, such as furniture or wall colour schemes, or it may involve designing the whole associative learning space as a pastiche. Initial discussions might focus on the kinds of spaces that denizens enjoy (or find productive); which elements of those spaces are perceived most central to their experiences there; and the extent of the pastiche that is possible and desirable within institutional space.

The underlying premise of the associative learning space is inspired by the commonly discussed distinction between 'space' and 'place', where a place is a space with meaning. People form, the premise goes, deeply meaningful relationships with particular places in their lives that may involve particular emotional states (such as comfort, conviviality or contemplation) and particular expectations (such as how to act, who will be there and what resources will be available). Those relationships, the premise continues, can be leveraged in other spaces where the same emotional states and expectations are desirable. The second part of that premise, in particular, is hotly contested by many human geographers, but that academic contestation has not prevented the associative learning space - from rooms with beanbags to full-blown cafés - from becoming increasingly prevalent in actual universities. All of those foundational issues might be frankly addressed in discussion, wherever healthy scepticism is raised. Yet there are a range of persistent tensions for how the associative learning space is manifest that will certainly need to be addressed, even if the broader premises are accepted by those stakeholders involved in the discussions. One such tension is that evoking associations is hardly something that can be achieved with precision; while another is that the associations being evoked are deeply cultural and societal. The associative learning space may thus inadvertently serve to exclude, for example by evoking confusion or unanticipated associations in people from disparate cultures and thereby disadvantaging particular denizens; while even denizens from locally dominant cultures may find that unwanted associations are evoked alongside those judged more desirable. The evocation of associations relies on denizens thinking in metaphors that necessarily have multi-voiced and vague interpretations. How far to take the metaphor is, therefore, a worthwhile issue to explore.

\section{The cognitively integrated learning space}

The cognitively integrated learning space is designed to be a part of the thinking and other actions in which its denizens are engaged. The cognitively integrated learning space works by providing a range of artefacts examples include information displays, writing surfaces or equipment from some professional or industry setting - arranged so that denizens can interact with them during their educational working. Those artefacts, it is envisaged, will become an integrated part of denizens' thinking. For some people the idea of the cognitively integrated learning space will seem counterintuitive. We have become habituated to the idea that thinking, and other human functions such as remembering, deliberating and decision-making, occur within the biological organ known as the brain. Yet that is not how many learning scientists view the situation; instead, it is suggested, thinking occurs within functional organs in which the mind is integrated with other parts of the body (including the hands and eyes), with the external artefacts that are explored and manipulated, and indeed with other people in team working situations. All of those components should be viewed as integral to, and indispensable for, how we learn as human beings. Discussants should be encouraged to think through particular examples of their working, especially where the general idea initially proves too difficult to grasp. We sometimes use the common phrase working out to describe how we cognitively approach the problems that confront us, which does carry some of the correct connotations. The cognitively integrated learning space aims to directly support our efforts to do that working out and to communicate our thinking to others.

A range of interrelated tensions characterise the concept of the cognitively integrated learning space. One such tension is manifest because some forms of working out require focused thinking and individual action, while 
others require team working and the display of working to others. Those priorities might simply be in direct tension for some spaces; but in other circumstances the core challenge is to support transitions between moments of working alone, in sub-groups, and across the whole room in plenary discussion - and the attendant transitions in how the associated tools and materials are seen as controlled by particular denizens. A second tension occurs between the notion that the space's artefacts are for manipulating and continually modifying, and the notion that they might provide a constant anchor point whose strength lies in their unchanging presence: once again this can often be productively viewed as the management of transitions between moments, this time between active working and the subsequent ambient display of information as a collective memory. A third tension arises where configurations of materials localised in particular spaces are difficult to move or to replicate elsewhere: this tension highlights issues of issues of transfer, both for students, who might rely - or have come to rely - on particular resources to undertake certain kinds of working out; and for professional staff, for whom cognitively integrated learning spaces can come to be seen as resourceintensive and associated with timetabling problems. Working out the kind of transitions that are required by denizens, and the extent to which those transitions can be reasonably supported, will be a worthwhile moment in stakeholder discussions.

\section{The socially integrated learning space}

The socially integrated learning space serves its denizens as a community. Denizens go there to meet with other members of the community and to engage in routine practices: whether those are the routines preferred by a denizen as an individual; or routines imposed by allotted responsibilities within the community, such as maintaining the space itself or its equipment. The socially integrated learning space often has some sort of history that is felt by its denizens as integral to their experience of the space. That history might be relatively short-term and personal - a particular group might attend the space often, having originally met there for some particular purpose and having enjoyed the experience. Understanding which spaces within an institution become socially integrated in that way will be a useful issue for collective reflection. Yet, equally, the history of a given space might be very longstanding - in some cases the space might have been used by succeeding generations of students over decades or centuries. In those instances, the attendant issue for discussion might be how to value, reinforce, or refine that longstanding social integration. In some cases, the history of the socially integrated learning space might be clearly visible: denizens might display their own work around the space, including on the walls; while, in other cases, the work of preceding generations of the community might be given a visual prominence. Either way, the fact that the space serves as part of the heritage of the denizen community might be consciously highlighted. To varying extents, the socially integrated learning space might feel ostentatiously historical, in the sense of evoking a prior historical period in its aesthetic; threadbare, evoking the shared camaraderie of students experiencing both intellectual discovery and financial thrift; and/or disciplinary, serving a community of denizens with a shared intellectual or professional mission.

One dilemma associated with the socially integrated learning space often concerns the nature of the learning that occurs there. The socially integrated learning space might be a bar or pub serving alcohol and offering games facilities; somewhere denizens might specifically go to escape their formal learning obligations for periods of time. Yet, nonetheless, their socialisation in that space forms an integral part of their overall educational experience. The socially integrated learning space might be associated with a student society perhaps one focusing on media production, language learning, or sport - where denizens are more obviously learning particular skills, but with potentially uncertain relationships between those skills and the formal university credentials they are pursuing. Or, conversely, the socially integrated learning space might be very readily associated with formal disciplinary identity: one example might be a studio of the kind that so often sits at the heart of art and design disciplines. Understanding and valuing the diverse contributions that socially integrated learning spaces make is, therefore, an important point for discussion. Another dilemma associated with the socially integrated learning space concerns the issue of ownership. The socially integrated learning space might be 'delinked', to some extent, from the centralised estates management oversight mechanisms that cover most institutional space, and instead owned by some denizen community or academic department. 
Such delinking sometimes brings with it the necessity of allocating responsibilities for the upkeep of the space, which may fall to denizens themselves, and the obligation to service ongoing financial costs imposed via institutional space-charging mechanisms. The latter may sometimes need to be met by academic departments or student societies. The advantages and implications of ownership therefore constitute an important issue for discussion and clarification - and, where the possibility exists, for negotiation between denizens and estates management.

\section{Concluding comments}

As the introduction explains in more detail, the present document arises from a symposium: The Future of Learning Spaces in Higher Education: Space, Technology and Pedagogy, hosted by the Higher Education Academy (now Advance HE) in York, UK on the 22 March 2018. When I heard about the event, I was immediately enthusiastic: learning spaces is an under-recognised field of enquiry. Yet, as the timetable emerged and was finalised, I realised that the event had unusual potential. The symposium having attracted both academic researchers and estates personnel, there was real potential for the kind of inter-professional and collaborative discussion about the topic that I have long sought to nurture and support.

And I was not disappointed! As the group convened to discuss learning spaces together, there was none of the negative stereotyping that occasionally dogs debates around the topic. At the start of the day, I presented (an earlier version of) the above vocabulary and handed out (an earlier version of) the poster diagram ${ }^{3}$, and was pleased that the resulting discussion encompassed both professionals and scholars. Overall, the day accommodated both scholarly and professional presentations, each of which provoked intelligent questions from across the mixed audience. The presentations - some subset of which have been written up to form the remainder of this document - drew out various aspects of how spaces mediate educational practices. Overall, the symposium entirely reinforced my conviction that stakeholders of different stripes coming together to discuss learning space production can be highly informative and useful. The symposium itself, along with the document you are now reading, can serve as a useful indicator of why talking about learning spaces is worthwhile. My main hope is that readers of this document are sufficiently stimulated to generate more such conversation in the future!

\section{References}

Adams Becker, S., Cummins, M., Davis, A., Freeman, A., Hall Giesinger, C., and Ananthanarayanan, V. (2017). NMC Horizon Report: 2017 Higher Education Edition. Austin, TX: The New Media Consortium.

Bligh, B. (2014). Examining new processes for learning space design. In P. Temple (Ed.), The Physical University: Contours of space and place in higher education (pp. 34-57). London: Routledge.

Bligh, B., and Crook, C. (2017). Learning spaces. In E. Duval, M. Sharples, and R. Sutherland (Eds.), Technology Enhanced Learning: Research themes (pp. 69-87). Springer.

Bligh, B., and Pearshouse, I. (2011). Doing learning space evaluations. In A. Boddington, and J. Boys (Eds.), Re-shaping Learning? A critical reader: the future of learning spaces in post-compulsory learning (pp. 3-18). Rotterdam: Sense Publishers.

Crook, C., and Bligh, B. (2016). Technology and the dis-placing of learning in educational futures. Learning, Culture and Social Interaction, 11, 162-175.

\footnotetext{
${ }^{3}$ PDF available online: $\underline{\text { https://archive.org/details/SpacelnfluencingEducationHEAEventDiagramMarch2018 }}$
} 
Ellis, R. A., and Goodyear, P. (2016). Models of learning space: integrating research on space, place and learning in higher education. Review of Education, 4(2), 149-191.

Nordquist, J. (2016). Alignment achieved? The learning landscape and curricula in health profession education. Medical Education, 50(1), 61-68.

Painter, S., Fournier, J., Grape, C., Grummon, P., Morelli, J., Whitmer, S., and Cevetello, J. (2013). Research on Learning Spaces Design: Present state, future directions. Ann Arbor, MI.: Society for College and University Planning.

Pearshouse, I., Bligh, B., Brown, E., Lewthwaite, S., Graber, R., Hartnell-Young, E., and Sharples, M. (2009). A Study of Effective Evaluation Models and Practices for Technology Supported Physical Learning Spaces (JELS): Final report. Bristol: JISC.

Luckin, R., Bligh, B., Manches, A., Ainsworth, S., Crook, C., and Noss, R. (2012). Decoding Learning: The proof, promise and potential of digital education. London: NESTA.

Temple, P. (2008). Learning spaces in higher education: an under-researched topic. London Review of Education, 6(3), 229-241.

Tierney, W. G., and Lanford, M. (2015). An investigation of the impact of international branch campuses on organizational culture. Higher Education, 70(2), 283-298.

Tight, M. (2012). Researching Higher Education ( $2^{\text {nd }}$ ed.). Maidenhead: Open University Press. 